\title{
Loneliness and the letter: Co-developing cross-generational letter writing with higher education students and older people
}

\author{
Georgina Binnie* - University of Leeds, UK
}

\begin{abstract}
Writing Back is an intergenerational letter-writing project that has been matching University of Leeds students as pen pals with older Yorkshire residents since 2014. Working in collaboration with a principal investigator based in the university's School of English, students and older participants have been facilitating conversation about loneliness, home and belonging via their exchange of cross-generational correspondence and their engagement with archival images of the county. This article reflects upon the successes and limitations of using co-productive letter writing and visual methodologies in qualitative loneliness research. In carrying out a narrative analysis of Writing Back's correspondence, it demonstrates how letter writing can be used as an effective methodological tool to generate new understanding of loneliness in multiple age demographics.
\end{abstract}

Keywords: loneliness; intergeneration; letter writing; qualitative; visual methodologies

\section{Key messages}

- Intergenerational correspondence can be used by students and older people to generate qualitative data on loneliness.

- Facilitating an engagement with local archival material can enable researchers to better understand the relationship between loneliness, home and belonging in students, as well as in long-standing, older members of the community.

- Co-productive methodologies are needed if researchers are to avoid recontextualizing personal correspondence when using this as project data.

\section{Introduction}

Loneliness is a universal experience (Mijuskovic, 1996), and one that we are all likely to encounter at some stage during our lives. While notoriously difficult to quantify, it is generally agreed to be the emotional state caused by the discrepancy between the amount of contact that we have and the amount of contact that we desire (Perlman and Peplau, 1981; de Jong-Gierveld, 1987). We can have multiple friends and family members yet still feel lonely and long for greater and more fulfilling human contact. Inspired by my experiences of loneliness and letter writing during my academic studies, I founded Writing Back in 2014, a project that aims to explore issues of loneliness in students and older people via the use of a cross-generational, letter-writing model. 
By matching University of Leeds students as pen pals with older Yorkshire residents, and encouraging them to write and share historical images with one another, the project generates a rich body of data that sheds new light on the relationship between loneliness, home and belonging in students and the older population.

\section{Loneliness and self-reflectivity}

Writing Back was born out of my experiences with loneliness and letter writing during my academic studies. I attended the University of Sheffield between 2007 and 2010, and quickly settled into university life, but there were still points at which I recognized that I was, for what felt like the first time, entirely alone. This social isolation prompted moments of loneliness, which were often alleviated by exchanging letters with my grandmother, Margaret. As Margaret was partially deaf and did not use a mobile phone or computer, our correspondence provided us with a welcome means of communication, and the sight of her handwriting was a source of comfort during these transitional periods. Margaret's letters revealed the issues associated with ageing after a bereavement, with comments including 'What a busy life you lead. A bit different from mine' (November 2010) and 'Now we are back to SILENCE in the flat - you can't have it all ways' (December 2010). Putting pen to paper evidently provided my grandmother with opportunities for self-reflection and stoicism; as she experienced later health difficulties, she continued to implore me to 'make the most of ... [my] youth' and 'hope for the best' (June 2013).

After beginning a PhD on 'James Joyce and Photography' at the University of Leeds in 2012, I started volunteering at Halcyon Court Care Home, Leeds, and teaching undergraduate students on Level 1 modules. The combination of these roles led me to recognize the similarities between these groups of people; just as the students often expressed a longing for home, so too did the care home residents. After observing the commonalities between these groups, I decided to pilot a cross-generational letterwriting scheme at the University of Leeds with a view to replicating the joy I had gained from writing to my grandmother with a wider audience. My experiences meant that I was able to empathize and interact with both age groups, and I knew that my story was contextually-bound and deeply intertwined with my position as a researcher (Sword, 1999: 277). As in the process of co-production, I also recognized that those who were or had been lonely would be best placed to assist in the design and development of this intergenerational model (INVOLVE, 2018).

\section{Loneliness in older and student populations}

The last decade has seen a surge in loneliness research, prompted in part by the work of organizations such as the Campaign to End Loneliness (www.campaigntoendloneliness. org) and the Silver Line (www.thesilverline.org.uk). This area of research is not a new phenomenon; as early as 1947, the Nuffield Foundation reported that 8 per cent of their UK sample of older people were 'very lonely' and 13.7 per cent were 'lonely at times' (quoted in Victor and Bowling, 2012: 314). The effects of loneliness can be severe; in a study of 2,173 people, Tjalling Jan Holwerda et al. (2014: 135) found that older people who were lonely were more likely to develop dementia, and the effects of social isolation on health in older adults have been deemed comparable to lack of exercise, obesity, smoking and high blood pressure (Cacioppo et al., 2011).

Older people who identify as being socially isolated or lonely are more likely to be admitted to hospital (Hastings et al., 2008), stay in hospital for longer 
(Landeiro et al., 2016) and be less resistant to infection (Cohen et al., 1997). These health-related impacts have an economic cost; McDaid et al. (2017: 6) estimate that older people who are severely lonely cost UK health and social care services in excess of $f 6,000$ per person over a ten-year period. Speaking about loneliness carries with it its own difficulties. In a seminal article, Frieda Fromm-Reichmann (1990: 313-14) argued that:

People who are in the grip of severe degrees of loneliness cannot talk about it; and people who have at some time in the past had such an experience can seldom do so either, for it is so frightening and uncanny in character that they try to dissociate the memory of what it was like, and even the fear of it.

The stigma and fear associated with loneliness create a paradox in which people frequently recognize and experience its effects yet are unable to readily discuss this with one another. Research by the Campaign to End Loneliness (2017) confirms this issue; in a study of 2,240 British adults, more than half (56 per cent) said that they would find it difficult to admit to being lonely, and three-quarters (76 per cent) said that they would 'find it hard to admit to feeling lonely' because they did not want to be a burden.

Loneliness is prevalent in younger people. In a survey of 2,256 UK adults, 36 per cent of 18-34 year olds worried about being lonely, compared with 17 per cent of over-55 year olds (Griffin, 2010). The psychological effects of loneliness were higher in Griffin's younger respondents, and 53 per cent of 18-34 year olds and 31 per cent of over-55 year olds felt depressed because of feeling alone (ibid.). Figures released by the Office for National Statistics support these variations in levels of loneliness; in data collected in England in 2016 and 2017, 10 per cent of 16-24 year olds, 6 per cent of 25-34 year olds and 3 per cent of 65 year olds often or always felt lonely (ONS, 2018). Older men living with a partner, who had strong neighbourhood connections and were in employment or retired were least likely to identify as being lonely (ibid.). While there is relatively little data on the cause of these variations, research has suggested that people become more resilient in tackling loneliness as they get older, and women may report being lonely more than men (ibid.).

Leeds has one of the largest student populations in the UK, and students tend to be concentrated in the Inner West and city centre (Leeds JSNA, 2015: 15). In Yorkshire, loneliness is a known issue and 6.84 per cent of people living in the region identify as being often or always lonely (ONS, 2017). This was the highest of all regional data sets, ahead of 6.44 per cent who were often or always lonely in the West Midlands (ibid.). Although Yorkshire's figures are likely to have in part been influenced by the inclusion of data from the Humber, work by the Silver Line, a charity for older people, supports the ONS findings; in a review of all calls made to their charity helpline between 2013 and 2016, the amount of calls made by residents in Yorkshire and the Humber was second only to those made in Greater London (Silver Line, 2016). For many students, studying away from home for the first time can lead to them experiencing homesickness, a sensation that, like loneliness, is associated with the perception that one's social network is inadequate (Leary, 2010: 881). The social mobility involved in attending university can cause disruptions in relationships and 'difficulties in adaptation to a new environment' (Cicognani et al., 2014: 42). In areas where loneliness levels are high, social interventions between students and older people can offer support to both parties. Students who are unfamiliar with their new cities have much to learn from its older residents and, by facilitating knowledge exchanges between both parties, it is possible to generate relationships that shed new light on approaches to loneliness. 


\section{Using correspondence in intergenerational qualitative research}

In a review of health and social interventions for older people, Ronzi et al. (2018: 310) found that mentoring programmes led to improved 'confidence, interactions and relationships and [people] feeling valued'. Intergenerational initiatives were found to have had a 'positive effect on various health outcomes' and, in 14 cross-generational studies, regular interaction between people of different ages led to participants feeling 'more valued, included and appreciated' (ibid.: 25-6). After examining 50 intergenerational studies, Canedo-García et al. (2017: 2) similarly concluded that they could result in improvements in health and well-being in older adults, contribute to positive behaviour changes in children and assist in the 'construction of identity amongst adolescents'. Although one of the studies detailed by Canedo-García involved a lifewriting workshop (Chippendale and Boltz, 2015), none of the interventions involved letter writing between different age groups, despite the dialogical and self-reflective nature of this social practice (Hall et al., 1999). Like the health-related programmes evaluated by Ronzi et al. (2018) and Canedo-García et al. (2017), letter writing has been found to be associated with 'physical and mental benefits across diverse samples' (Pennebaker and Seagal, 1999: 1252). More specifically, in a 'short [letter] writing campaign' involving 219 people, writing letters of gratitude was found to improve well-being and significantly decrease 'levels of depressive symptoms' (Toepfer et al., 2012: 198).

Correspondence has been used in feminist and activist research (Plummer et al., 1993), in literacy studies (Hall et al., 1999) and to gather qualitative data on women's self-harming (Harris, 2002: 2). Letters span boundaries between formal and informal discussion (Barton and Hall, 2000), and public and private life (Maybin, 2000). They can be used to generate conversation and can provide opportunities for writers to become 'reflectively aware of their experiences' (Kralik et al., 2000: 912). As 'documents of life' (Stanley, 2013: 3), letters offer narrative researchers the chance to better understand 'how participants experience, live, and tell about their world' (Keats, 2009: 181). Studies tend to involve researchers exchanging letters with participants (Plummer et al., 1993; Hall et al., 1999; Maybin, 2000; Harris, 2002), using writing as a tool for professional self-reflection (Channa, 2017) and encouraging people to '(re)produce themselves, their practices, and their communities' (Prior, 2009: xii). The role of the researcher in such studies can be problematic. Reflecting on her use of correspondence to better understand women's self-harming, Harris (2002: 11) recognized that, while the writers had given 'their life stories freely', she had given them nothing in return. The use of correspondence as a qualitative data source has been criticized by those who view letters as 'informal, personalized accounts, stating unsubstantiated opinions' (Plummer et al., 1993: 306) and others who see it as an 'impersonal communication medium' (Kralik et al., 2000: 909). While correspondence can be informal, letters can still provide researchers with access to 'private and personal areas' of someone's life in a form that can rarely be considered impersonal (Harris, 2002: 15).

\section{Visual research}

Having completed a PhD on 'James Joyce and Photography', I wanted to combine an interest in historical, archival images with letter writing when establishing Writing Back. In the first year of the project (2014/15), students were provided with copies of First World War letters by Special Collections at the Brotherton Library; in subsequent 
years, a broader theme of Yorkshire has led to historical images being provided to pen pals by the M\&S (Marks \& Spencer) Company Archive, ULITA (the University of Leeds International Textiles Archive), West Yorkshire Joint Archive Service, Leodis at Leeds Libraries and the Leeds Gypsy and Travellers Archive. Photographs are 'embedded in the social world' (Rose, 2016: xxii) and can be used to inspire 'competing and contested, meanings and interpretations' (Hall, 1997: 9). Like correspondence, the exchange of images can allow participants to explore topics that might prove more challenging in conventional interview settings, provoking discussion beyond the 'material trace' of the image (Harrison, 2002: 105).

Just as letters are a form of social history, so too are photographs. Images are forms of 'cultural narration' that are deeply embedded in 'specific contexts and practices' (ibid.). Photographs can reveal hidden stories and can be used by participants to communicate 'who they are and where they have come from' (ibid.). In visual research, photo elicitation is a participatory research method used in interview settings to inspire individual or group reflection and community empowerment via the showing of photographic images (Schumann, 2015: 77). Writing Back combines elements of this methodology by allowing participants to select archival images of Yorkshire to send to their pen pals. The exchanging of these images enables the students to become familiar with the wider community, and the older partners to share their personal histories in return. The relationship between the archival images and notions of home and belonging further allows the pen pals to generate qualitative data on loneliness, as explored in the 'Correspondence from Writing Back's archive' section of this article.

\section{Writing Back: Practicalities}

Writing Back was established in 2014 using a 1500 grant from the Leeds for Life Foundation (https://leedsforlife.leeds.ac.uk/Home/TheFoundation). I ran the pilot year of the project as a non-research initiative to test the logistics of the scheme. While I knew that I wanted to explore issues of loneliness in both age groups, advertising the project as a loneliness intervention initially proved problematic; interested participants were either hesitant to self-identify as lonely or felt that this issue did not apply to them. A reluctance to publicly acknowledge loneliness was corroborated in research by Agarwal and Brydges (2018), who found after running a social intervention for older people that the participants did not want to discuss their own feelings of loneliness and instead preferred to identify this in their peers. In recruiting pen pals to the project, I stressed the benefits of the knowledge exchanges that might be generated by their involvement and emphasized that, while they may not self-identity as being lonely, they could still help others who might be experiencing its effects.

After approaching the University of Leeds Volunteering Hub, I received guidance on working with volunteers, project management and developing training materials. I visited local Leeds-based charities and churches and recruited 14 older Yorkshire residents to the project. I appointed the same number of School of English students using targeted emails and lecture shout-outs. The student recruitment was a relatively straightforward task, given my ability to contact multiple students at one time. Enlisting older pen pals was a more time-consuming process, as while multiple older people might be interested in joining the project, at another local meeting I might only recruit one or two participants to the scheme. In a 2016 review of the barriers faced by older volunteers, poor health, lack of skills, time constraints and caring responsibilities were seen to negatively impact upon recruitment and retention (Southby and South, 2016: 2). 
I encountered some of these issues when speaking to older participants, as many said that they were too busy or physically unable to write letters, that they did not want to write to a student or thought that their English language skills were too poor. To aid recruitment, I stressed that the project was non-time-intensive, that costs for writing and transport to events were covered and that all letters would be exchanged via the university.

I provided training on signposting concerns and case scenarios to the students, and outlined the practicalities of the scheme, such as the recommendation that they write to one another once every other week. Letters could be handwritten or typed, so long as they were sent in the post. Students were asked to handwrite their letters unless they were physically unable to do so, or their older partner expressed a preference for them writing in print. The sending of letters via a university pigeonhole avoided addresses being released to participants, and the digitization of student letters prior to them being sent provided a form of safeguarding. Some of the older pen pals were housebound, having learnt about the project via Leeds Libraries at Home Service, so training was provided for older pen pals in the form of posted information booklets and guidelines to sign and return. The pen pals also completed registration documents in which they detailed their interests and hobbies. I sought to match participants based on similar interests. The students wrote the first letters, and while there was no set template, we discussed what this might involve at the training session. It was agreed that asking sensitive but thought-provoking questions could help to facilitate positive discussions and produce longer letters. A record was kept of all letters that were posted, and this monitoring process continues to guard against letters going missing or participants unexpectedly stopping writing. The project has received annual ethical approval from the University's Ethics Board.

Figure 1: Number of pen pals enrolled in Writing Back since 2014

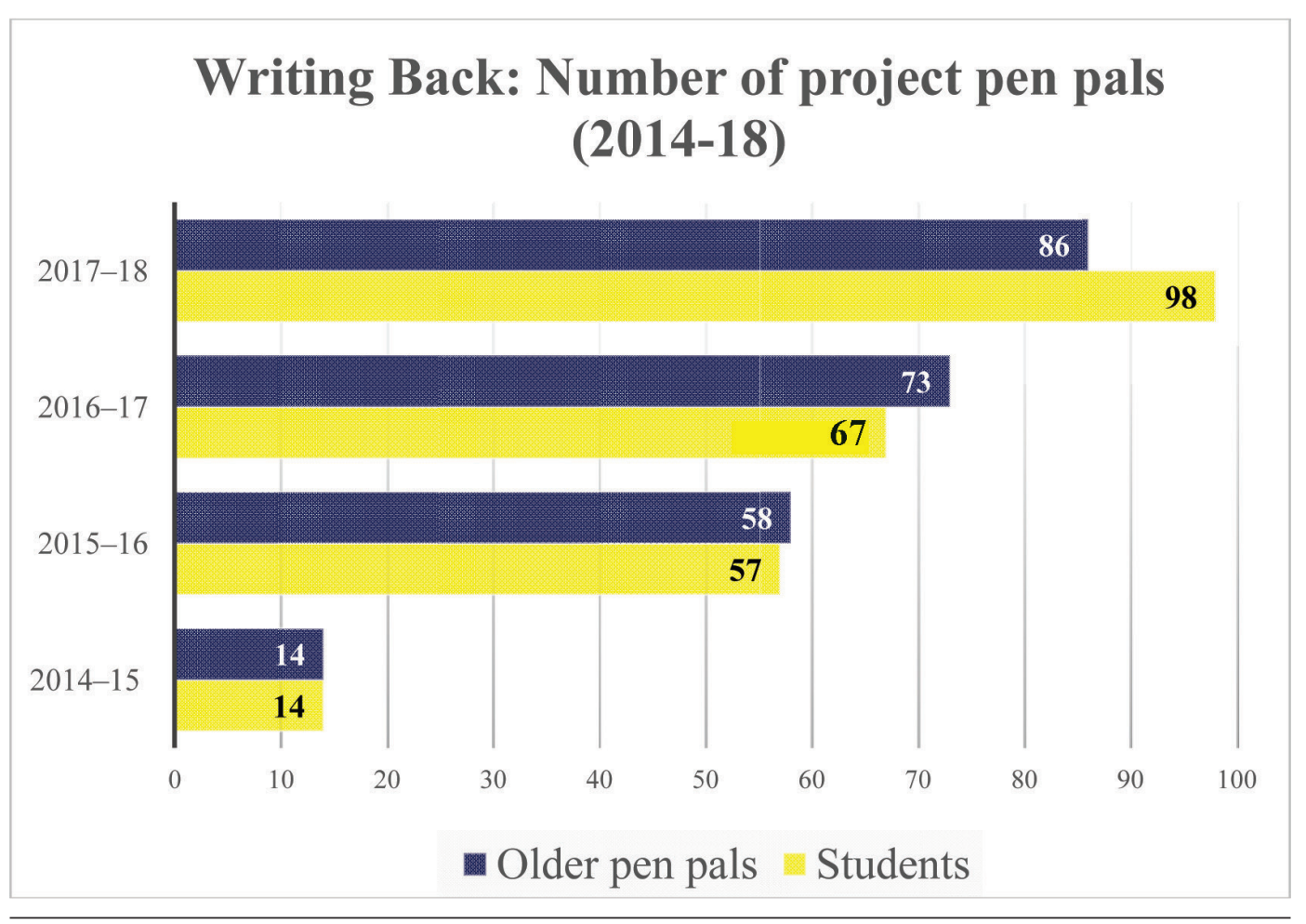


In 2015/16 and 2017/18, funding for the project was provided by the School of English, University of Leeds. In 2016/17, the Footsteps Fund: Making a World of Difference Campaign (https://campaign.leeds.ac.uk/footsteps-fund) awarded a grant to the scheme. This funding covered the costs of stationery, postage, transport for older pen pals, and for myself to visit third-sector organizations, and refreshments for meet-up events. Each year, the number of pen pals has increased (see Figure 1), in part thanks to news coverage of the project in The Yorkshire Post and The Guardian and on BBC Radio Leeds, BBC Radio Sheffield and Woman's Hour on BBC Radio 4. Returning pen pals have sometimes taken on more than one correspondent, leading to variations in the ratio of students and older participants.

My membership of Leeds City Council's Age-Friendly Partnership has also aided recruitment, and the city's Neighbourhood Networks and health-care providers have referred older pen pals to the scheme. When participants have dropped out part-way through the year, for example due to ill health or a change in circumstances, additional participants have been recruited so that the pen pal has the opportunity to write to another person.

Participants complete questionnaires at the start and the end of the year. These documents provide space for self-reflective comments on letter writing, loneliness, ageing and the community. The pen pals' feedback has enabled the collaborative development of the letter-writing model, such as the addition of a pre-Christmas meeting where pen pals can meet at an earlier stage of the year. With the 2017/18 cohort, a revised version of Ann Bowling et al.'s (2002) Older People's Quality of Life questionnaire (OPOOL-35) has been used, along with the Loneliness Measurement Tool produced by the Campaign to End Loneliness (2015). While the OPQOL-35 is usually reserved for over-65 year olds, a 'not applicable' option was added to this survey to reflect changes in circumstances between the younger and older participants. It was thought helpful to gather similar data on participants' health, social relationships, independence, home, neighbourhood and financial circumstances, psychological well-being and leisure activities (Bowling et al., 2002). The findings from this year $(2017 / 18)$ are still being written up, but they should provide useful sociodemographic information about the pen pals.

The questionnaires provide quantitative and qualitative data, but it is the correspondence that has proved most enlightening when evaluating the different age groups' approaches to loneliness. The students' letters are digitized before being posted and the older participants' correspondence is copied at the end of the year. Pen pals are provided with complete booklets of their exchange of letters, and can choose whether anonymized versions are used for research or publicity purposes. The act of correspondence is a two-way process and a letter has 'two parents, the writer and the recipient' (Ponsonby, 1923: 2). Writing Back's pen pals have autonomy over the production and dissemination of their letters. This means that where one pen pal does not give permission for their correspondence to be used, or a student does not leave the letters they have received to be digitized, they cannot be viably used as a form of research data. The implications of this are discussed in the penultimate section of this article.

\section{Correspondence from Writing Back's archive}

Writing Back's pen pals shape the course of their discussion in their letters. They are made aware of the project's objective to use cross-generational correspondence to better understand loneliness but many will not directly approach this topic, instead 
preferring to discuss loneliness via homesickness and the role of the community. In turning to Writing Back's letters, I have been careful to consider the participants' social and cultural experiences and the context of this correspondence (Cresswell, 2013). Letters are a form of narrative, with the latter term being used here to define texts in which 'events are selected, organised, connected, and evaluated as meaningful for a particular audience' (Riessman, 2005: 1). In approaching the pen pals' letters through the lens of narrative inquiry, I have sought to better understand how the participants use stories and memory sharing in their letter writing to respond to project themes. All participants have been renamed and have consented to the use of their anonymized letters in research.

In a first letter to her older pen pal Myrna, student Abbey wrote: 'I am really loving my time in Leeds, at first I was very homesick but as I got into my new course and met new people I really started to love it' (November 2015). In her second letter, Abbey expanded upon this experience of homesickness, reflecting:

I wanted to join this scheme because I am an English and History student and I was interested in looking at the archive but also, when I started Uni I found it immensely difficult and I liked the idea of corresponding with someone as at the time I didn't do that and struggled to tell my parents I felt homesick. (December 2015)

As Shaver et al. (1985: 214) have noted, the transition to university can involve 'a major social and psychological upheaval', particularly in a student's first semester, and students entering university 'would be wise to expect a ... temporary loss of social support'. Difficulties can arise if loneliness is unexpected or if it conflicts with a student's preconceived ideas about university. For Abbey, these difficulties were further exacerbated by her 'struggle' to tell her parents about what she was feeling. Meeting new people provided her with a chance to alleviate these feelings of homesickness and, in her letter, she noted that she had 'really started to love [university]' after connecting with other people (Abbey, November 2015). Prior to writing to Myrna, Abbey had only received brief details about her pen pal, but the thought involved in this exchange and the tactile nature of the letters - provided her with space for self-reflection and learning.

When Writing Back's pen pals explicitly engage with the subject of loneliness, this tends to be in association with notions of community and belonging. In a second letter to her older pen pal Helen, student Eliza wrote, 'I love getting mail! I hope we become good friends too! It's nice having someone I'm in contact with in Leeds sometimes I feel a bit lonely too, just because I'm not from here' (January 2017). This revelation was probably in part inspired by her older pen pal's openness in revealing in a previous letter that she 'was really pleased to receive [her correspondence]' and had, due to a marriage breakdown some 36 years previously, experienced a 'very low period' (Helen, January 2017). The sharing of personal emotions allowed for the discussion of more sensitive topics, but this was also aided by Helen having already overcome this 'low period'.

In her correspondence, Helen revealed that she had 'kept on going' and had returned to university, studying for a degree while raising three children (ibid.). For Eliza, these revelations enabled the formation of their friendship and enhanced her enjoyment of the scheme; in her letter, she acknowledged, 'I'm so glad to be part of this project too! ... I was so pleased to get your letter, it's something to look forward to every week or so' (January 2017). For Hall et al. (1999: 139), the use of 'too' in correspondence signifies an 'acceptance of the dialogic nature of letter writing' 
and enables 'common ground ... to be established'. Eliza's linguistic choice of 'too' in 'I'm so glad to be part of this project too' allowed her to establish a bond with her older partner and connect with the wider community. The trust associated with the act of writing probably encouraged her to reveal these moments of homesickness, prompting Helen's empathetic response.

In a first letter to his student partner Georgia, Paul revealed that he was 'really looking forward to exchanging history and ideas', before writing 'My wife died just over 2 years ago ... which would have been our 55th wedding anniversary. I am only now getting used to living alone' (March 2017). In acknowledging the conversational and self-reflective nature of their correspondence, Paul revealed that 'this summary of the details of ... [his] life' was a 'way of opening up the dialogue' with his student partner (ibid.). Paul's letters were filled with moments of stoicism, as when he further reflected, 'I have been through a few ups and downs. I like to think I am in the process of living with loneliness' (ibid.). As a way of alleviating loneliness, Paul had joined a group for bereaved people and was 'trying to make use of all the time [he had]' (ibid.).

The death of a partner can lead to increased feelings of loneliness (Dury, 2014) and, while Stroebe et al. (2005) suggest that the effects of this loss on emotional loneliness cannot be mediated by social support, Paul and Georgia's letters attest to the positive influence of conversation on well-being. Georgia responded with empathy and understanding to Paul's bereavement, acknowledging:

It sounds as if you have made great progress in the past couple of years.

... That is a great outlook to have in life - I have always been brought up

to live everyday as if it is my last one. (April 2017)

For Georgia, this positive attitude was further aided by the act of writing. Responding to Paul's news that he regularly wrote a diary, she similarly revealed: 'I write a diary every day ... I find that writing things down about my life and mood is a brilliant way to calm myself down' (ibid.). While both participants had developed coping strategies to improve their levels of well-being, their correspondence also provided them with emotional benefits. In his end-of-year questionnaire, Paul reflected that their crossgenerational friendship had helped to change his 'opinion of modern youth' and had taught him that 'There is hope for this world' (May 2018). The scheme helped to change Georgia's perceptions of ageing and loneliness; in her end-of-year feedback she recognized, 'Ageing can be a hard process but the pen pal scheme has shown me that it doesn't have to be a lonely time' (May 2018).

\section{Using archival images in participatory research}

Historical, post-1900s photographs of Yorkshire are provided to Writing Back's pen pals by Special Collections at the Brotherton Library, the M\&S Company Archive, ULITA, West Yorkshire Joint Archive Service, Leodis at Leeds Libraries and the Leeds Gypsy and Travellers Archive. These images are collated into booklets that are distributed to participants at the start of the year. The current selection of images includes advertisements for Marks \& Spencer, photographs of textile workers and post-1950s images of Yorkshire town centres. The pen pals are told that their partner may not always have lived in Leeds or Yorkshire, and website links and physical directions are provided to the archival holdings. Participants can request that alternative images are found for them, if none of the photographs prove suitable. In 2017/18, older pen pals were provided with the booklets for the first time, as well as the younger participants. Previously, students have taken sole charge of selecting and sending images. This 
has led to rich, cultural knowledge exchanges in which older partners have shared personal histories in return. It is hoped that by providing all ages with these images, the participants will be able to further engage with Yorkshire's cultural heritage.

Researchers can use visual images with participants to generate discussion about 'who they are and where they have come from' (Harrison, 2002: 105). In Writing Back, the pen pals control this discussion, and their selection and exchange of images frequently expose the relationship between loneliness and belonging. In 2017, a student pen pal, Anna, sent an image of Kirkgate Market to her older penfriend, Doris, describing how, 'As part of the Writing Back project, they have given me a collection of photos from around Yorkshire from the last 100 years or so. I've added one to this letter of Kirkgate Market (sorry about the folding!)' (February 2017) (see Figure 2).

\section{Figure 2: Kirkgate Market, c. 1900, M\&S Company Archive}

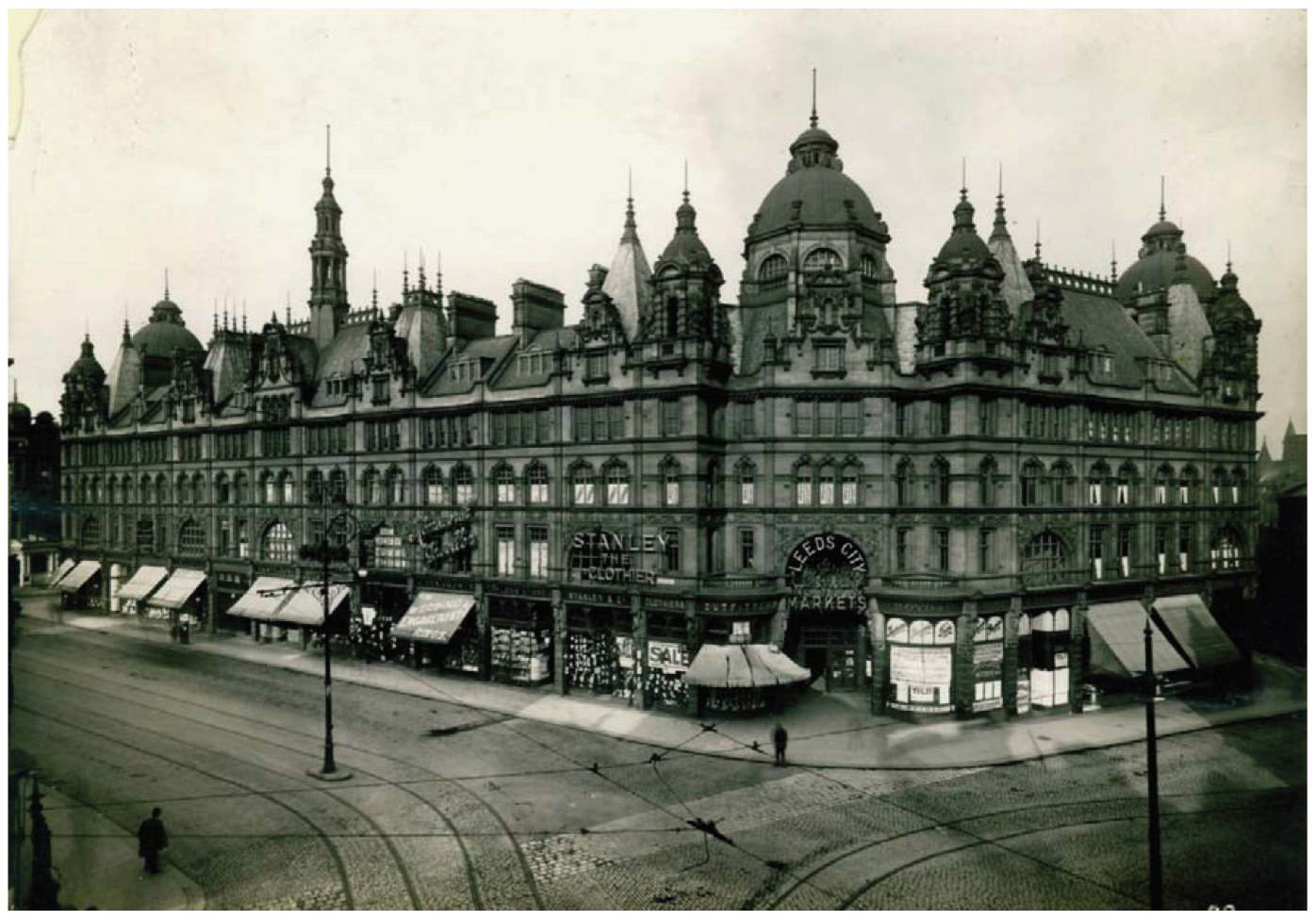

Reflecting on why she had chosen this image, Anna wrote, 'I passed the market earlier today ... It must be one of the only places in the city that hasn't changed hugely over the years' (ibid.). Receiving the picture '[sparked] off all kinds of memories' for Doris, and she revealed in the following letter:

Leeds used to have some lovely big department stores. Most were clothes shops with resident seamstresses or milliners \& the beautiful dresses \& hats made a lovely display. When I was 21 I bought a navy blue Chanel suit with a light waist, a fitted jacket with $3 / 4$ sleeves edged with white pique cuff which had to be removed, washed \& stitched back on every time I wore it. I seem to slob around in trousers in my new life - most comfortable - no need for tights. People used to dress smartly to go to the shops in town. Not many bother to do that now. (February 2017) 
For Doris, this photo elicitation provoked a response in which she was able to merge memories of her youth with reflections on her current life, with her references to clothing further illustrating social and generational changes.

As in the transitional stages experienced by Writing Back's younger pen pals, Doris had recently moved to 'a small retirement apartment', leaving her susceptible to loneliness. In her correspondence she noted that, while she thought she 'would live as a recluse', instead life was 'rather busy at times' (January 2017). Their empathetic exchange of images and stories led Anna to recognize, 'It seems everybody has some connection and that the world is quite a small place' (February 2017). While Anna did not self-identify as lonely, she did disclose that she had spoken to her mother 'about ageing' and had worried about her mother living alone due to a heart condition (ibid.). The correspondence between Doris and Anna allowed them to develop trust in one another, and Doris subsequently praised Anna's mother for her 'bravery' and revealed that she had suffered a bereavement (February 2017). As in the letters sent by Paul and Georgia, Doris and Anna's correspondence attests to the importance of conversation and social relationships in 'living with loneliness' (Paul, March 2017), adapting to the community and ageing well.

\section{Challenges and project successes}

\section{Using correspondence and photographs in qualitative research}

Using letters in research inevitably involves a process of recontextualization, particularly if this correspondence is moved 'into different arenas and used for different purposes' (Barton and Hall, 2000: 9). By allowing participants to control the production and dissemination of their letters, Writing Back goes some way towards circumventing this issue. However, the pen pals' autonomy over whether their letters are used in research does mean that only around 25 per cent of correspondence is used for this purpose. Given this relatively low percentage, more could be done with future cohorts of pen pals to avoid creating a hierarchy between 'data' and 'interpretation' and simply encompassing their stories 'within the text of 'the author" (Plummer et al., 1993: 306). In subsequent years, the pen pals will be invited to carry out a narrative analysis of their own letters. A greater move towards co-productive methodologies will also see participants being invited to contribute to and reflect upon project reports before these reach completion. While the pen pals have generally engaged well with photographs of Yorkshire, they will soon be invited to produce or exchange their own images connected with key project themes. As in the narrative analysis, pen pals will reflect upon the meaning behind these photographs and will be asked what they can teach us about future approaches to alleviating and researching loneliness.

\section{Measuring impact}

In evaluating public engagement projects, it is essential that researchers question whether their interpretational activities have 'produced appropriate and accountable knowledge-claims' (Stanley, 2013: 5). Writing Back is not currently tested as an applied health intervention, and more might be done in the future to quantify its impact. However, the current questionnaires do attest to the positive influence of intergenerational letter writing on both age demographics. In the end-of-year questionnaires (2015/16), 89 per cent of students $(n=19)$ and 91 per cent of older participants $(n=34)$ agreed that writing to their pen pal had a positive effect on their mental well-being. In their freeform feedback, the older pen pals variously acknowledged the benefits of writing 
to the students as: keeping their 'brains working' (Leila, 2016), allowing them to stay 'up to date with how young people are tackling life' (Thomas, 2016) and providing 'a blessing for those ... [who] need to write to hone our skills of communication and keep our brain active' (Valerie, 2016). Further elaborating upon the physical benefits of their correspondence, one older pen pal described the project as having encouraged them to keep their 'mind focus[ed]' and exercise their 'fingers and wrist movements' (Harriet, 2016). In the same year, a student reflected, 'I would recommend this scheme to everyone. There seems to be a certain degree of stigma around having friends that are older but my pen pal became exactly that - a friend' (Hannah, 2016).

In 2016/17 feedback, an older participant noted, 'I live alone and it is really nice to receive a letter and take time to write back about what I have been doing or what I have done in the past' (Jane, 2017). Another advised, 'I find my pen pal's letters to be a breath of fresh air and it enables me to formulate my thoughts and reflect on what I have been doing and how that makes me feel' (Sandra, 2017). For the students, the benefits of the project were similarly profound; one revealed, 'My favourite thing about letters is their relative permanence - being able to look back on them and remind you of good memories (or bad) while revealing the transience of each period of life' (Cara, 2017). Another acknowledged:

Letters and letter writing seem like a great way to combat loneliness both for students and the older generation ... it seems therapeutic to me as well and distracts you from problems and stresses of everyday life. It is something to look forward to! (Emily, 2017)

Data from this year's cohort (2017/18) are still being analysed, but it is hoped that the information gathered using Ann Bowling and colleagues' (2002) OPQOL-35 will shed further light on the volunteers' motivations for joining the project and the links between home environments, social relationships and loneliness. Future cohorts of pen pals will be asked to use a loneliness measurement tool at the start and the end of the programme, and one-to-one interviews will be carried out with interested participants. Intergenerational correspondence will remain the project's primary method of data collection and will continue to be used to evaluate how we might better understand responses to loneliness in students and older people.

\section{Conclusion}

Writing Back is a project that is 'genuine and cyclical in nature', where the results of the engagement are 'used to influence the organisation's future actions and direction' (Age UK, 2011: 2). A greater move towards self-reflective, co-research practices should allow participants to continue to challenge the stigmas associated with loneliness and contribute to the development of this letter-writing model. As the sole Principal Investigator of Writing Back with a current cohort of 184 pen pals, my time is inevitably split between the competing demands of running the scheme and fulfilling other academic duties. In future research bids, I will explore collaborative opportunities with other institutions. Since 2014, I have made a commitment to the project's pen pals and they in turn have aided the formation and growth of this scheme. The wealth of data produced in their correspondence and questionnaires attests to the benefits of engaging with the public in loneliness research. As one older pen pal recently acknowledged of Writing Back, 'It's such a great idea getting young and old ages staying up-to-date with how they're tackling life. Writing to my student friend changes my day-to-day way of living' (Norma, 2017). 


\section{Notes on the contributor}

Georgina Binnie is an Impact and Research Fellow at the University of Leeds, and is the founder of the Writing Back project. From an initial cohort of 28 participants, she has grown the scheme to an award-winning and pioneering project involving 184 people. Writing Back was a finalist in the Individual-led Projects category at the National Co-ordinating Centre for Public Engagement's Engage Awards 2016. Dr Binnie is a member of Leeds City Council's Age-Friendly Board, who are working to ensure the success of Leeds as a World Health Organization Age-Friendly Community.

\section{References}

Agarwal, G. and Brydges, M. (2018) 'Effects of a community health promotion program on social factors in a vulnerable older adult population residing in social housing'. BMC Geriatrics, 18, Article 95, 1-11. Online. https://tinyurl.com/ycc6b2sk (accessed 4 November 2018).

Age UK (2011) Engaging with Older People Evidence Review. London: Age UK. Online. https://tinyurl.com/ycmee2wr (accessed 4 November 2018).

Barton, D. and Hall, N. (2000) 'Introduction'. In Barton, D. and Hall, N. (eds) Letter Writing as a Social Practice. Amsterdam: John Benjamins, 1-14.

Bowling, A., Banister, D., Sutton S., Evans, O. and Windsor, J. (2002) 'A multidimensional model of the quality of life in older age'. Aging and Mental Health, 6 (4), 355-71.

Cacioppo J.T., Hawkley L.C., Norman G.J. and Berntson, G.G. (2011) 'Social isolation'. Annals of the New York Academy of Sciences, 1,231 (1), 17-22.

Campaign to End Loneliness (2015) Measuring your Impact on Loneliness in Later Life. Online. www.campaigntoendloneliness.org/wp-content/uploads/Loneliness-MeasurementGuidance1.pdf (accessed 5 September 2018).

Campaign to End Loneliness (2017) 'The loneliness epidemic: Research reveals loneliness in older age "more likely than ever"'. Press release, 22 September. Online. https://tinyurl.com/y7oo6kwa (accessed 4 November 2018).

Canedo-García, A., García-Sánchez, J.-N. and Pacheco-Sanz, D.-I. (2017) 'A systematic review of the effectiveness of intergenerational programs'. Frontiers in Psychology, 8 (1,882), 1-13.

Channa, L.A. (2017) 'Letter writing as a reflective practice: Understanding the shuffling, shifting, and shaping of a researcher identity'. Reflective Practice, 18 (3), 358-68.

Chippendale, T. and Boltz, M. (2015) 'Living legends: Students' responses to an intergenerational life review writing program'. Journal of the American Geriatrics Society, 63 (4), 782-8.

Cicognani, E., Klimstra, T. and Goossens, L. (2014) 'Sense of community, identity statuses, and loneliness in adolescence: A cross-national study on Italian and Belgian youth'. Journal of Community Psychology, 42 (4), 414-32.

Cohen, S., Doyle, W.J., Skoner, D.P., Rabin, B.S. and Gwaltney, J.M. (1997) 'Social ties and susceptibility to the common cold'. JAMA, 277 (24), 1940-4.

Creswell, J.W. (2013) Qualitative Inquiry and Research Design: Choosing among five approaches. 3rd ed. Thousand Oaks, CA: SAGE Publications.

de Jong-Gierveld, J. (1987) 'Developing and testing a model of loneliness'. Journal of Personality and Social Psychology, 53 (1), 119-28.

Dury, R. (2014) 'Social isolation and loneliness in the elderly: An exploration of some of the issues'. British Journal of Community Nursing, 19 (3), 125-8.

Fromm-Reichmann, F. (1990) 'Loneliness'. Contemporary Psychoanalysis, 26 (2), 305-30.

Griffin, J. (2010) The Lonely Society? London: Mental Health Foundation. Online. www.mentalhealth. org.uk/publications/the-lonely-society (accessed 5 April 2018).

Hall, N., Robinson, A. and Crawford, L. (1999) 'Young children's explorations of letter writing'. In Barton, D. and Hall, N. (eds) Letter Writing as a Social Practice. Amsterdam: John Benjamins, 131-50.

Hall, S. (ed.) (1997) Representation: Cultural representations and signifying practices. London: SAGE Publications.

Harris, J. (2002) 'The correspondence method as a data-gathering technique in qualitative enquiry'. International Journal of Qualitative Methods, 1 (4), 1-9.

Harrison, B. (2002) 'Photographic visions and narrative inquiry'. Narrative Inquiry, 12 (1), 87-111. 
Hastings, S.N., George, L.K., Fillenbaum G.G., Park, R.S., Burchett, B.M. and Schmader, K.E. (2008) 'Does lack of social support lead to more ED visits for older adults?'. American Journal of Emergency Medicine, 26 (4), 454-61.

Holwerda, T.J., Deeg, D.J.H., Beekman, A.T.F., van Tilburg, T.G., Stek, M.L., Jonker, C. and Schoevers, R.A. (2014) 'Feelings of loneliness, but not social isolation, predict dementia onset: Results from the Amsterdam Study of the Elderly (AMSTEL)'. Journal of Neurology, Neurosurgery and Psychiatry, 85 (2), 135-42.

INVOLVE (2018) Guidance on Co-Producing a Research Project. Southampton: INVOLVE. Online. https://tinyurl.com/y7e8ll5b (accessed 4 November 2018).

Keats, P.A. (2009) 'Multiple text analysis in narrative research: Visual, written, and spoken stories of experience'. Qualitative Research, 9 (2), 181-95.

Kralik, D., Koch, T. and Brady, B.M. (2000) 'Pen pals: Correspondence as a method for data generation in qualitative research'. Journal of Advanced Nursing, 31 (4), 909-17.

Landeiro F., Leal, J. and Gray A.M. (2016) 'The impact of social isolation on delayed hospital discharges of older hip fracture patients and associated costs'. Osteoporosis International, 27 (2), 737-45.

Leary, M.R. (2010) 'Affiliation, acceptance, and belonging: The pursuit of interpersonal connection'. In Fiske, S.T., Gilbert, D.T. and Lindzey, G. (eds) Handbook of Social Psychology (Vol. 2). 5th ed. Hoboken, NJ: Wiley, 864-97.

Leeds JSNA (Joint Strategic Needs Assessment) (2015) Executive Summary: Cross-cutting themes. Leeds: Leeds City Council. Online. https://democracy.leeds.gov.uk/documents/s131982/10\%20 1\%20jsna\%20may\%2007\%20draft\%20v15.pdf (accessed 5 November 2018).

Maybin, J. (2000) 'Death row penfriends: Some effects of letter writing on identity and relationships'. In Barton, D. and Hall, N. (eds) Letter Writing as a Social Practice. Amsterdam: John Benjamins, 151-78.

McDaid, D., Bauer, A. and Park, A-L. (2017) Making the Economic Case for Investing in Actions to Prevent and/or Tackle Loneliness: A systematic review: A briefing paper. London: London School of Economics and Political Science. Online. https://tinyurl.com/y8ng624w (accessed 4 November 2018).

Mijuskovic, B. (1996) 'The phenomenology and dynamics of loneliness'. Psychology: A Journal of Human Behavior, 33 (2), 41-51.

ONS (Office for National Statistics) (2017) 'Measuring national well-being: Domains and measures'. Online. www.ons.gov.uk/peoplepopulationandcommunity/wellbeing/datasets/ measuringnationalwellbeingdomainsandmeasures (accessed 4 November 2018).

ONS (Office for National Statistics) (2018) 'Loneliness - what characteristics and circumstances are associated with feeling lonely?'. Online. https://tinyurl.com/y9kpd4g4 (accessed 4 November 2018).

Pennebaker, J.W. and Seagal, J.D. (1999) 'Forming a story: The health benefits of narrative'. Journal of Clinical Psychology, 55 (10), 1243-54.

Perlman, D. and Peplau, L.A. (1981) 'Toward a social psychology of loneliness'. In Duck, S. and Gilmour, R. (eds) Personal Relationships 3: Personal relationships in disorder. London: Academic Press, 31-56.

Plummer, G., Newman, K. and Winter, R. (1993) 'Exchanging letters: A format for collaborative action research?'. Educational Action Research, 1 (2), 305-14.

Ponsonby, A. (1923) English Diaries: A review of English diaries from the sixteenth to the twentieth century with an introduction on diary writing. London: Methuen.

Prior, P.A. (2009) Writing/Disciplinarity: A sociohistoric account of literate activity in the academy. New York: Routledge.

Riessman, C.K. (2005) 'Narrative analysis'. In Kelly, N., Horrocks, C., Milnes, K., Roberts, B. and Robinson, D. (eds) Narrative, Memory and Everyday Life. Huddersfield: University of Huddersfield Press, 1-7.

Ronzi, S., Orton, L., Pope, D., Valtorta, N.K. and Bruce, N.G. (2018) 'What is the impact on health and wellbeing of interventions that foster respect and social inclusion in community-residing older adults? A systematic review of quantitative and qualitative studies'. Systematic Reviews, 7 , Article 26, 1-22. Online. https://tinyurl.com/y8dsrrkx (accessed 4 November 2018).

Rose, G. (2016) Visual Methodologies: An introduction to researching with visual materials. 4th ed. London: SAGE Publications.

Schumann, R.L. (2015) 'Historic landscapes as cooperative animation: Exploring networks of memory with photographic methods'. In Hanna, S.P., Potter, A.E., Modlin, E.A., Carter, P. and Butler, D.L. (eds) Social Memory and Heritage Tourism Methodologies. London: Routledge, 71-91. 
Shaver, P., Furman, W. and Buhrmester, D. (1985) 'Transition to college: Network changes, social skills, and loneliness'. In Duck, S. and Perlman, D. (eds) Understanding Personal Relationships: An interdisciplinary approach. London: SAGE Publications, 193-219.

Silver Line (2016) 'Helpline for older people names UK's loneliness calls hotspots'. Press release, 10 November. https://tinyurl.com/ydypf2le (accessed 4 November 2018).

Southby, K. and South, J. (2016) Volunteering, Inequalities and Public Health: Barriers to volunteering: Summary report. London: Volunteering Matters. Online. https://tinyurl.com/ ybm2y3so (accessed 4 November 2018).

Stanley, L. (ed.) (2013) Documents of Life Revisited: Narrative and biographical methodology for a 21st century critical humanism. Farnham: Ashgate Publishing.

Stroebe, M., Stroebe, W. and Abakoumkin, G. (2005) 'The broken heart: Suicidal ideation in bereavement'. American Journal of Psychiatry, 162 (11), 2178-80.

Sword, W. (1999) 'Accounting for presence of self: Reflections on doing qualitative research'. Qualitative Health Research, 9 (2), 270-8.

Toepfer, S.M., Cichy, K. and Peters, P. (2012) 'Letters of gratitude: Further evidence for author benefits'. Journal of Happiness Studies, 13 (1), 187-201.

Victor, C.R. and Bowling, A. (2012) 'A longitudinal analysis of loneliness among older people in Great Britain'. Journal of Psychology, 146 (3), 313-31. 